\title{
A Laboratory Investigation into the Effects of Coarse Aggregate Angularity on Performance of WMA
}

\author{
Jie Ji $\mathbb{D}^{1,2}$ Peng Zhai, ${ }^{1}$ Wenhua Zheng, ${ }^{1}$ Zhi Suo, ${ }^{1,2}$ and Ying Xu ${ }^{1,2}$ \\ ${ }^{1}$ School of Civil Engineering and Transportation, Beijing University of Civil Engineering and Architecture, Beijing 100044, China \\ ${ }^{2}$ Beijing Advanced Innovation Center for Future Urban Design, Beijing University of Civil Engineering and Architecture, \\ Beijing 100044, China \\ Correspondence should be addressed to Jie Ji; jijie@bucea.edu.cn
}

Received 12 January 2018; Accepted 29 April 2018; Published 4 June 2018

Academic Editor: María Criado

Copyright ( $\odot 2018$ Jie Ji et al. This is an open access article distributed under the Creative Commons Attribution License, which permits unrestricted use, distribution, and reproduction in any medium, provided the original work is properly cited.

\begin{abstract}
This study evaluated the effects of coarse aggregate angularity (CAA) on the performances of warm mix asphalt (WMA) because previous studies have predominantly focused on the effects of CAA on the hot mix asphalt (HMA) performances. Five different CAAs were fabricated using Los Angeles abrasion test, and the digital image processing method was used to identify the CAA. Five mixes with different combinations of CAA and Sasobit-modified asphalt binder were prepared according to the Marshall mix design procedure. The performances such as the resistance to rutting and thermal cracking, moisture susceptibility, and volumetric characteristics of WMA were evaluated. The test results indicated that the CAA value was linearly declined with the abrasive wearing passes increased. Higher CAA value improved the potential to resistance to rutting of WMA but was not suitable to enhance the resistance to thermal cracking of WMA due to sharp corners that caused higher stress concentration. In addition, WMA was more prone to develop numerous macrocracking, which resulted in lower moisture susceptibility due to higher CAA value inducing higher air void, VMA, and VCA of WMA.
\end{abstract}

\section{Introduction}

Since 1999, warm mix asphalt (WMA) has been served as a new environment-friendly technology for trying to substitute the conventional hot mix asphalt (HMA). At present, compared with the conventional HMA, these technologies allow for WMA with temperature reductions of 10 to $50^{\circ} \mathrm{C}$. The temperature reductions obtained for WMA have beneficial effects on the environment, since they are related to less fuel use and reduced emissions for construction of asphalt mixtures. Therefore, WMA has been popularly used worldwide in a variety of applications [1-3]. However, studies conducted at the National Center for Asphalt Technology (NCAT) indicated that as the mixing temperatures are reduced for WMA, the mixtures show increased tendencies toward rutting and moisture susceptibility [4-6]. In the production of WMA, the aggregate may not be completely dried due to its lower temperature. Therefore, some residual moisture will keep in aggregates, which can break down asphalt aggregate bonds, and then the pavements will suffer from premature deterioration. Additionally, it is generally known that the aggregate constitutes approximately $95 \%$ of asphalt mixture by weight. They comprise the majority of asphalt mixture volume. Aggregates should be well proportioned to develop a stable skeleton for asphalt mixture. The physical properties of coarse aggregates, such as particle size, shape, elongation, orientation, texture surface, and angularity, are more significant in new generation asphalt mixtures. High coarse aggregate angularity (CAA) supports better aggregate interlocking and interactions with asphalt binder. However, previous studies have been focused on the effects of CAA on the conventional HMA, a very limited works has explored on the performance of WMA influencing by CAA. Huang et al. [7] researched the effects of CAA and asphalt binder on laboratory-measured permanent deformation properties of HMA and pointed that coarse aggregate imaging system (AIMS), uncompacted voids in coarse aggregate (VCA), and triaxial tests were related to the CAA and laboratory-measured rutting indices. At 
temperatures close to the asphalt binder's upper grade limit, aggregate structures played a critical role in the rutting resistance of HMA, whereas, at temperatures below the asphalt binder's upper grade limit, the stiffness of the asphalt binder played a more important role in the rutting resistance of HMA. Leon and Charles [8] studied a method of evaluating the effect of CAA on HMA performance and its relationship to the permanent deformation resistance. The test results showed there was an increase in the resistance of HMA to permanent deformation with the CAA value increased. Souza et al. [9] noted the overall effect of angularity on the mixtures' resistance to fracture damage was positive because aggregate blended with higher CAA value requires more asphalt binder to meet mix design criteria, which mitigates cracking due to increased viscoelastic energy dissipation from the asphalt binder, while angular particles produce a higher stress concentration that results in potential cracks. Rao et al. [10] studied the effects of CAA on the shear strength properties of HMA and granular base layers in pavements and developed the new angularity index (AI). It showed the AI value computed for the HMA could be correlated to the angle of internal friction and thus the shear strength properties of the HMA. Pan and Tutumluer [11] measured the elongate and angularity of coarse aggregate using digital image processing (DIP) method and established the surface toughness index. Shu et al. [12] found that CAA has significant effects on the rutting performance of HMA when the asphalt binder grade is critical to the environment. The effect of CAA of less angular coarse aggregate on the rutting performance of HMA was closely related to the depth of the mixtures. Wang et al. [13] evaluated the CAA using DIP method and pointed the roughness factual dimension and surface parameter could characterize the CAA. The test results presented that the CAA had a good correlation with aggregate size. The CAA became smaller with the increase of aggregate size. Yuan [14] studied the CAA influencing on the performances of HMA and suggested the moisture susceptibility of HMA decreased, but the dynamic stability increased with the CAA value increased. Liu et al. [15] studied the CAA index and recommended two new CAA indexes, angular index of radius method $\left(\mathrm{IA}_{\mathrm{rm}}\right)$ and angle index of gradient method $\left(\mathrm{IA}_{\mathrm{gm}}\right)$. The test results found the $\mathrm{IA}_{\mathrm{rm}}$ and $\mathrm{IA}_{\mathrm{gm}}$ had a linear correlation with $I_{\mathrm{ap}}$ obtaining from ASTM D3398-97. Chen et al. [16] measured the CAA of seven different coarse aggregates and evaluated the effects of CAA on the performances of HMA. The test results indicated the CAA had different influence on the performances of HMA. Leon and Charles [17] studied the coarse aggregate type and angularity impacted on permanent deformation of HMA and pointed the aggregate type as well as CAA had a significant effect on the permanent deformation and also that with an increased in CAA, there was an increase in the resistance of mixes to permanent deformation. Link and Kuo et al. [18] presented the correlation between the permanent deformation of HMA and their aggregate geometric irregularities and found the aggregate geometric irregularities had a strong correlation with the permanent deformation of HMA using regression analyses.
TABle 1: Physical properties of Sasobit.

\begin{tabular}{lccc}
\hline Items & $\begin{array}{c}\text { Specific gravity } \\
\left(\mathrm{g} / \mathrm{cm}^{3}\right)\end{array}$ & Melting point $\left({ }^{\circ} \mathrm{C}\right)$ & $\begin{array}{c}25^{\circ} \mathrm{C} \text { penetration } \\
(0.1 \mathrm{~mm})\end{array}$ \\
\hline Sasobit & 0.953 & 103 & 0 \\
Spec. & - & $98-110$ & $\leq 1$ \\
\hline
\end{tabular}

To this end, most of the relevant studies have focused on the effects of CAA on the resistance to permanent deformation and skid resistance of HMA. However, few researches have examined the role of CAA related to volumetric characteristics and performances of WMA.

\section{Objectives and Experimental Scope}

This study aimed to investigate the effects of CAA on volumetric characteristics and performances of WMA. The experimental scope of this study was the following:

(i) The limestone coarse aggregate was abrasive wore for $0,250,500,750$, and 1000 passes using the Los Angeles abrasion apparatus to obtain five different CAAs. The CAA values were calculated by means of the DIP method.

(ii) The SK-90 was used for base asphalt binder, and Sasobit-modified asphalt binder was prepared by the addition of 3\% Sasobit into the SK-90 asphalt binder.

(iii) The type of WMA was AC-13F (China Specification). Five WMAs with different combinations of CAA and Sasobit-modified asphalt binder were prepared according to the Marshall mix design procedure.

(iv) The performances, such as resistance to rutting and thermal cracking, moisture susceptibility, and volumetric characteristics, such as air void, VMA, VCA, VFA, Marshall stability, and flow value of WMA, were evaluated.

(v) The performances of WMA related to CAA were explored through the integrated experimentalcomputational approach.

\section{Test Materials, Methods, and Mixture Design}

3.1. Test Materials. The SK-90 asphalt binder used in this study was obtained from South Korea. Sasobit used as an organic wax additive could completely be soluble in the asphalt binder at temperatures above $105^{\circ} \mathrm{C}$. It reduced the temperature at which the mixtures were produced and compacted and consumes at an application rate of $3 \%$ by mass of SK-90. Sasobit and SK-90 were blended at $120^{\circ} \mathrm{C}$ and stirred for 5-10 min manually. Physical properties of Sasobit, SK-90, and Sasobit-modified asphalt binder are listed in Tables 1 and 2. Their properties met the technical requirements specified by China.

The mineral aggregate used in this study was limestone. The nominal maximum size of the coarse aggregate was $16 \mathrm{~mm}$. The coarse aggregate was sieved and partitioned 
TABLE 2: Physical properties of SK-90 and Sasobit modified asphalt binder.

\begin{tabular}{lcccccc}
\hline Asphalt binders & $\begin{array}{c}25^{\circ} \mathrm{C} \\
\text { penetration } \\
(0.1 \mathrm{~mm})\end{array}$ & $\begin{array}{c}15^{\circ} \mathrm{C} \text { ductility } \\
(\mathrm{cm})\end{array}$ & $\begin{array}{c}\text { Softening } \\
\text { point }\left({ }^{\circ} \mathrm{C}\right)\end{array}$ & $\begin{array}{c}60^{\circ} \mathrm{C} \text { dynamic } \\
\text { viscosity }(\mathrm{Pa} \cdot \mathrm{s})\end{array}$ & $\begin{array}{c}\text { Mass loss }(\%) \\
\text { Penetration ratio }(\%)\end{array}$ & $\begin{array}{c}10^{\circ} \mathrm{C} \text { ductility } \\
(\mathrm{cm})\end{array}$ \\
\hline $\begin{array}{l}\text { SK-90 } \\
\begin{array}{l}\text { Sasobit-modified asphalt } \\
\text { binder }\end{array}\end{array}$ & 79 & $>100$ & 52.8 & 141.2 & -0.113 & 61.3 \\
\hline
\end{tabular}

TABLe 3: Physical properties of limestone.

\begin{tabular}{lcc}
\hline Size sieve $(\mathrm{mm})$ & $\begin{array}{c}\text { Apparent specific } \\
\text { gravity }\left(\mathrm{g} / \mathrm{cm}^{3}\right)\end{array}$ & $\begin{array}{c}\text { Bulk specific } \\
\text { gravity }\left(\mathrm{g} / \mathrm{cm}^{3}\right)\end{array}$ \\
\hline $9.5-16.0$ & 2.852 & 2.699 \\
$4.75-9.5$ & 2.822 & 2.696 \\
$0-4.75$ & 2.662 & - \\
Filler & 2.702 & - \\
\hline
\end{tabular}

into two size fractions, namely, 9.5 to $16.0 \mathrm{~mm}$ and 4.75 to $9.5 \mathrm{~mm}$. The fine aggregate was sieved and partitioned into 0 to $4.75 \mathrm{~mm}$. Filler was limestone powder. Physical properties of limestone aggregates are presented in Tables 3 and 4 and satisfied with the technical requirements specified by China.

\subsection{Test Methods}

3.2.1. Quantification of CAA. Aggregate angularity, which can be defined herein as the measurement of the sharpness of the corners of a particle, has been recognized as a primary factor influencing on the interlock between aggregates and performances of asphalt mixtures. But now, there is no recognized method of measuring CAA in China or other countries. The current methods used in practice have several limitations: they are laborious, are subjective in nature, and/or lack a direct relationship with the fundamental parameters governing performance such as shear strength and stiffness $[19,20]$. However, the testing procedures for CAA have been well established and are specified by ASTM standards and AASHTO standards; for example, the ASTM D5821 and AASHTO TP 61 are used for measuring the CAA, but they are indirect test methods and yield a single index not reflecting CAA clearly [21, 22]. Additionally, it is specified that an attempt should be made to suggest appropriate testing methods that are more objective, scientific, and reliable to quantify CAA. Recently, the DIP method has been actively developed to account for the CAA. A number of DIP techniques, for example, X-ray tomography, laser profiling, and photogrammetry, have been used. Chandan et al. [23] researched the texture, angularity, and form of aggregate particles using DIP method and described CAA by means of a gradient-based method. Maerz and Lusher $[24,25]$ tested various shape factors of coarse aggregate using the DIP method, including principal axis ratios, roundness, sphericity, and angularity. Mora and Kwan [26], and Carlos [27] analyzed the particle size and shape of coarse aggregate using DIP and measured the shape parameters, including sphericity, shape factor, convexity ratio, and so on.
Fletcher et al. [28, 29] designed a unified computerautomated system to present the shape of fine and coarse aggregates. The developed system was used to measure aggregate shape properties for a wide range of fine and coarse aggregates. Swift [30] involved a comparative analysis between well-established physically performed measurements for coarse aggregate and an image-based system and characterized the coarse aggregate angularity using the DIP method. Hence, the DIP is an approach that the aggregate images can be obtained and processed though high-solution computational technique. It provides the capability of quick and accurate measurement of the characteristics of aggregates, such as shape, elongation, surface texture, and angularity, and also the means for the development of automated methods for aggregate characteristics analysis.

In this study, the DIP method is employed to measure the CAA and includes three parts: First, the white and black images are captured using high-resolution automated digital camera. Second, the gray images are transformed clearly by means of gray intensity technology. Finally, after the images are segmented using threshold, the Image Pro-Plus (IPP) software is adopted to obtain the geometric parameters, including perimeter, area, long axis, and short axis of shape of coarse aggregates; the data were amounts of pixels, and calculate the CAA value. In addition, in order to quantify the CAA, the concept of equivalent ellipse is implemented during the image processing procedure. On basis of the concept of equivalent ellipse, the CAA is a ratio of convex perimeter of aggregate particles to perimeter of equivalent ellipse of aggregate particles. In the hypothesis, the shape of coarse aggregate is assumed as equivalent ellipse, and the equivalent ellipse has the same major and minor axes, but has no angularity, as shown in Figure 1. The CAA value can be expressed as

$$
\text { CAA }=\frac{\text { perimeter }_{\text {convex }}-\text { perimeter }_{\text {ellispse }}}{\text { perimeter }_{\text {ellispse }}} \times 100 \%,
$$

where CAA is the angularity for one single coarse aggregate (\%), perimeter ${ }_{\text {convex }}$ is the convex perimeter for one single coarse aggregate (pixel), and perimeter ${ }_{\text {ellispse }}$ is the perimeter of equivalent ellipse for one single coarse aggregate (pixel).

Based on (1), the CAA value for one single coarse aggregate is evaluated. The CAA value for either a circle or an ellipse will be zero. For angular particles, their CAA values will be lower than 100 . Therefore, higher CAA value indicates a higher degree of angularity. Actually, the coarse aggregate should have a well-proportioned used in mixture. For example, in this study, the ratio of weight of these three sizes of aggregate in WMA was $1: 4: 4$. To get the mean CAA 
TABLE 4: The sieving of limestone.

\begin{tabular}{lcccccccccc}
\hline \multirow{2}{*}{ Size sieve $(\mathrm{mm})$} & \multicolumn{9}{c}{ Passing ratio (\%) } & \multicolumn{1}{c}{ } \\
& 16 & 13.2 & 9.5 & 4.75 & 2.36 & 1.18 & 0.6 & 0.3 & 0.15 & 0.075 \\
\hline Filler & 100.0 & 100.0 & 100.0 & 100.0 & 100.0 & 99.9 & 99.8 & 99.4 & 97.6 & 82.7 \\
$0-4.75$ & 100.0 & 100.0 & 100.0 & 94.8 & 68.8 & 49.4 & 36.5 & 27.8 & 23.1 & 17.1 \\
$4.75-9.5$ & 100.0 & 100.0 & 97.8 & 25.8 & 6.7 & 4.8 & 4.0 & 3.7 & 3.4 & 2.9 \\
$9.5-16.0$ & 100.0 & 95.6 & 41.2 & 7.8 & 4.2 & 3.5 & 3.3 & 3.1 & 2.9 & 2.4 \\
\hline
\end{tabular}

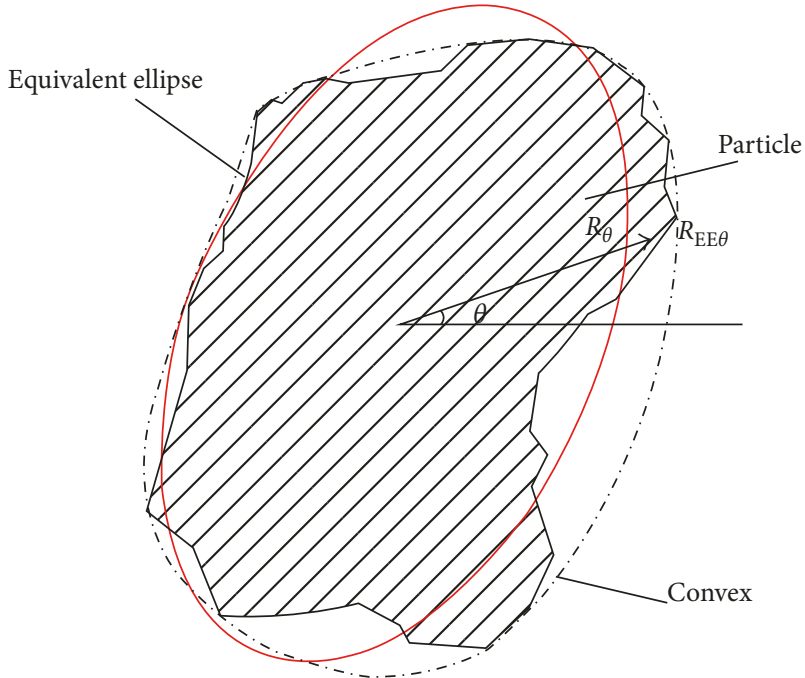

FIGURE 1: Schematic diagram of particle equivalent ellipse.

value used in the mixture, the CAA value for one single limestone coarse aggregate is weighted, and then the mean CAA value can be calculated, as shown in (2):

$$
\overline{\mathrm{CAA}}=\frac{\sum_{i=1}^{n} \mathrm{CAA}_{i} \times \text { area }_{i}}{\sum_{i=1}^{n} \text { area }_{i}},
$$

where the mean CAA represents whole coarse aggregates used in mixture (\%), the CAA represents the number $i$ coarse aggregate (\%), and area $_{i}$ represents the number $i$ coarse aggregate (pixel).

3.2.2. Los Angeles Abrasion Test. To obtain the different CAA value, the different sizes of limestone coarse aggregates were abrasive wore for $0,250,500,750$, and 1000 passes using the Los Angeles abrasion apparatus according to the ASTM C131 procedure, respectively [31]. To avoid the coarse aggregate breakage by steel ball, the steel ball was removed during the process of abrasive wearing.

3.3. Mixture Design. Due to use Sasobit as organic wax additive, the mixture was termed as WMA. The WMA type was $\mathrm{AC}-13 \mathrm{~F}$, and the target air voids of all the specimens were $4 \pm 1.0 \%$. The OAC (optimal asphalt content) of the WMA was determined in accordance to the Marshall mix design procedures ASTM D1559 and the resultant OAC was $4.6 \%$ [32]. The gradation and performances of the WMA specimens met the technical requirements specified by China, which can be seen in Tables 5 and 6 .
TABLE 5: Gradation of WMA.

\begin{tabular}{lcccccccccc}
\hline $\begin{array}{l}\text { Size Sieve } \\
(\mathrm{mm})\end{array}$ & 16 & 13.2 & 9.5 & 4.75 & 2.36 & 1.18 & 0.6 & 0.3 & 0.15 & 0.075 \\
\hline $\begin{array}{l}\text { Passing } \\
\text { ratio (\%) }\end{array}$ & 100 & 95 & 75 & 55 & 40 & 28 & 20 & 15 & 10 & 5 \\
$\begin{array}{l}\text { Upper } \\
\text { limit (\%) }\end{array}$ & 100 & 100 & 85 & 68 & 50 & 38 & 28 & 20 & 15 & 8 \\
$\begin{array}{l}\text { Lower } \\
\text { limit (\%) }\end{array}$ & 100 & 90 & 68 & 38 & 24 & 15 & 10 & 7 & 5 & 4 \\
\hline
\end{tabular}

TABLE 6: Performances of WMA.

\begin{tabular}{lcccc}
\hline Items & $\begin{array}{c}\text { DS } \\
(\text { passes } / \mathrm{mm})\end{array}$ & $\begin{array}{c}\text { Maximum failure } \\
\text { stress }(\mu \varepsilon)\end{array}$ & $\begin{array}{c}\text { Residual } \\
\text { stability (\%) }\end{array}$ & TSR (\%) \\
\hline Mix & 1160 & 2376 & 80.80 & 90.99 \\
Spec. & $\geq 1000$ & $\geq 2000$ & $\geq 80$ & $\geq 75$ \\
\hline
\end{tabular}

To produce consistent specimens for laboratory testing, the same gradation, $\mathrm{OAC}$, and other testing conditions were selected for all WMA specimens with different limestone CAA value.

3.4. Volumetric Characteristics. Eight cylinder specimens with $101.6 \mathrm{~mm}$ in diameter and $63.5 \mathrm{~mm}$ in height compacted with Marshall compactor were fabricated and then the volumetric characteristics of WMA mixes, such as air void, VMA (Voids in Mineral Aggregate), VFA (Voids Filled with Asphalt), VCA (Percent Air Voids in Coarse Aggregate), Marshall stability, and flow value, were performed according to the ASTM D2726 and ASTM D1559 $[32,33]$.

\subsection{Mixture Performances}

(i) Eight cylinder specimens with $101.6 \mathrm{~mm}$ in diameter and $63.5 \mathrm{~mm}$ in height compacted with Marshall compactor were fabricated for each WMA conducting the moisture susceptibility of WMA in accordance with AASHTO T283 [34].

(ii) Three specimens with $300 \mathrm{~mm}$ in length, $300 \mathrm{~mm}$ in width, and $50 \mathrm{~mm}$ in depth for each WMA were prepared for measuring the resistance to rutting of WMA using the T0719-2011 method specified by China [35]. This test is conducted by applying a smooth solid-steel wheel load on each wheel is $0.7 \mathrm{MPa}$ and traveling at a speed of $42 \pm 1$ passes $/ \mathrm{min}$ on WMA specimens at $60^{\circ} \mathrm{C}$ test temperature and measuring the resultant total rutting depth with time during $60 \mathrm{~min}$, and then the ratio of total traveling 


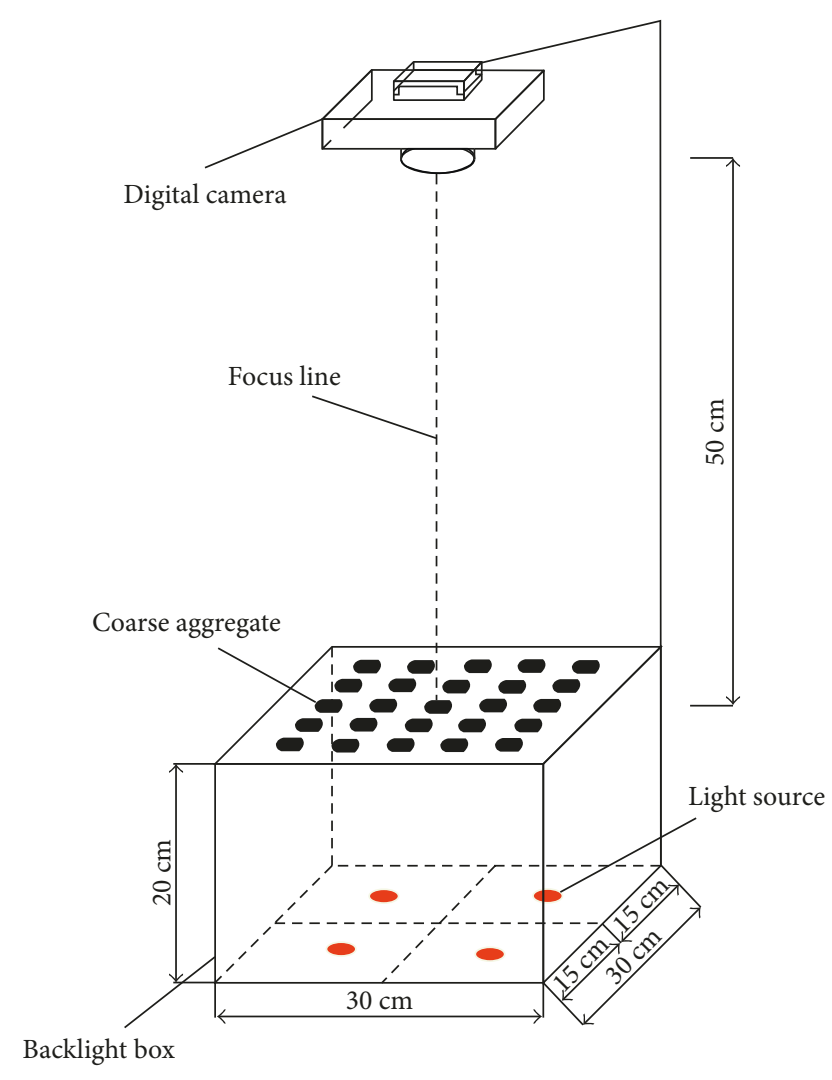

FIgURE 2: The configuration of backlight box.

passes to minute, called as dynamic stability, is calculated for reflecting the resistance to rutting of WMA.

(iii) Three specimens with $250 \mathrm{~mm}$ in length, $30 \mathrm{~mm}$ in width, and $35 \mathrm{~mm}$ in depth for each WMA were trimmed for testing the resistance to thermal cracking of WMA through the T0715-2011 method specified by China [35]. This test is conducted by applying a loading on WMA specimens at $-10^{\circ} \mathrm{C}$ test temperature (the loading rate is $50 \mathrm{~mm} / \mathrm{min}$ ) until the specimen failure. The maximum failure stress is calculated for evaluating the resistance to thermal cracking of WMA.

\section{Results and Discussions}

4.1. Evaluation of CAA. During the capturing of black and white images of limestone coarse aggregates, for avoiding the light influencing the image clarity, the "backlight box" device was developed, which can be seen in Figure 2. This device was equipped with bottom light source, top aggregate tray, and automated digital camera. These components give the system the capability of capturing black and white images of limestone coarse aggregates, as well as gray images of limestone coarse aggregate surfaces.

In this section, $13.2 \mathrm{~mm}$ limestone coarse aggregate with 500 abrasive wearing passes was used as an example to explain how calculated the CAA value using DIP method. The processing steps were the following: (i) The limestone coarse aggregates were set in the fifth row and the fifth line in the tray and five coarse aggregates were displayed in each row and line, which resulted in twenty-five coarse aggregates totally, as observed in Figure 3(a).

(ii) The $214 \times 214$ pixels white and black images of aggregates were captured using Nikon digital camera with 1200 million pixels, as presented in Figure 3(a).

(iii) The images were processed using gray processing and image intensity technology, as illustrated in Figure 3(b).

(iv) The clear gray images were converted into the binary images by means of segmentation threshold method, as seen in Figure 3(c).

(v) The images were processed by the IPP software, which numbered each aggregate and the geometric factors, such as perimeter, area, long axis, short axis and so on, were obtained, as demonstrated in Figure 3(d).

(vi) The total information for $13.2 \mathrm{~mm}$ limestone coarse aggregate with 500 abrasive wearing passes was input into the IPP software, and the CAA value were calculated automatically, as listed in Table 7

Followed by (2), the mean CAA for $13.2 \mathrm{~mm}$ limestone coarse aggregate with 500 abrasive wearing passes was calculated, and the mean CAA value was $6.433 \%$. Consequently, according to the above method, the mean CAA value for $13.2 \mathrm{~mm}, 9.5 \mathrm{~mm}$, and $4.75 \mathrm{~mm}$ limestone coarse aggregates with $0,250,500,750$, and 1000 abrasive wearing passes were evaluated, respectively, as presented in Figure 4.

Figure 4 indicates that the CAA value for $13.2 \mathrm{~mm}$, $9.5 \mathrm{~mm}$, and $4.75 \mathrm{~mm}$ limestone coarse aggregates had the similar tendency related to the abrasive wearing pass. The CAA value decreased with the abrasive wearing passes increased and had a linear correlation with their abrasive wearing passes. The correlation coefficients $R^{2}$ were higher than 0.930, which demonstrated an increase in abrasive wearing passes contributing to a reduction in the CAA value. The slopes of the regression lines were negative with the $13.2 \mathrm{~mm}, 9.5 \mathrm{~mm}$, and $4.75 \mathrm{~mm}$ limestone coarse aggregates, which also indicated that increase in abrasive wearing pass results in decreased in CAA value. The absolute value of the slope decreased as the size of coarse aggregate became larger which illustrated CAA value was less sensitive to the size of coarse aggregate. The ranking of CAA value in reduction with the abrasive wearing pass increased was $4.75 \mathrm{~mm}$, followed by $9.5 \mathrm{~mm}$ and $13.2 \mathrm{~mm}$ limestone coarse aggregates, which presented the smaller size coarse aggregate was more prone to be worn and loss its angularity. Additionally, under the identical condition of the abrasive wearing passes, the smaller size coarse aggregate had a higher CAA value due to its higher specific surface area and fractured surfaces with more crushing. However, once the smaller size coarse aggregate was subjected to abrasive wearing, it was more prone to lose its angularity compared to the larger size coarse aggregate. Figure 5 is an example of partial $4.75 \mathrm{~mm}$ limestone coarse aggregate before and after abrasive wearing. 


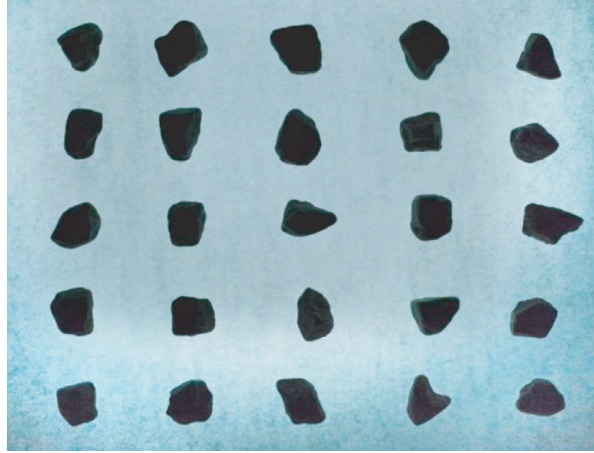

(a)

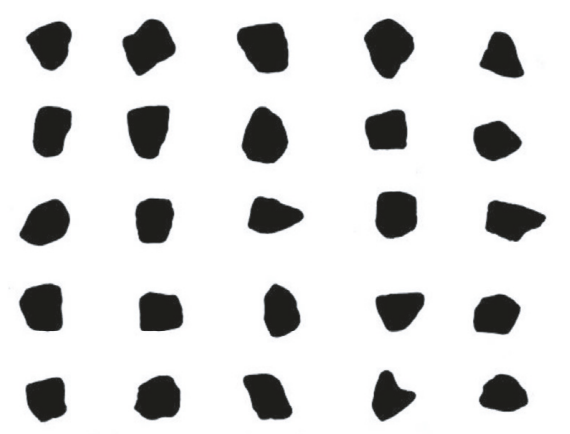

(c)

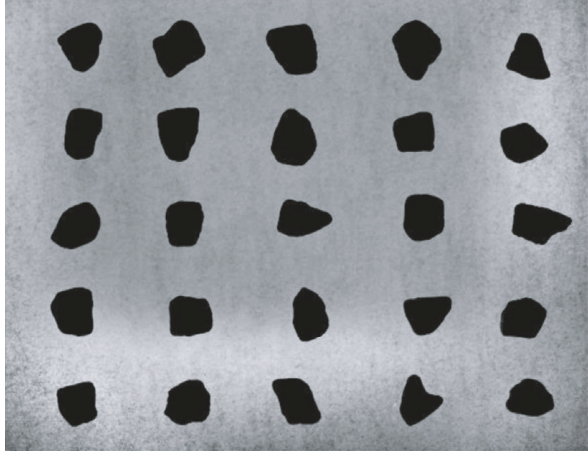

(b)

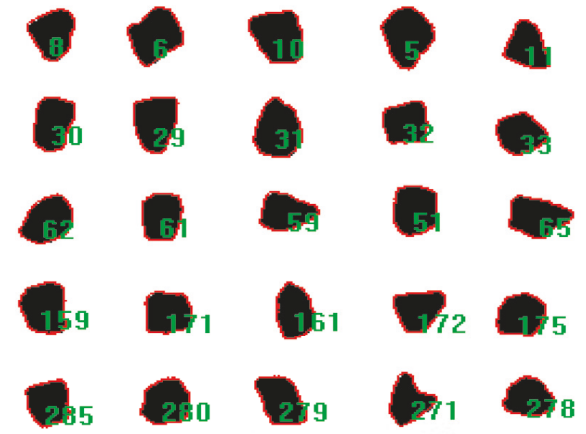

(d)

Figure 3: The CAA processing steps. (a) Original image of $13.2 \mathrm{~mm}$ aggregate. (b) Gray image of $13.2 \mathrm{~mm}$ aggregate. (c) Binary image of $13.2 \mathrm{~mm}$ aggregate. (d) Number of each $13.2 \mathrm{~mm}$ aggregate.

TABLE 7: Quantitative results of CAA.

\begin{tabular}{|c|c|c|c|c|c|}
\hline Number & Area & Perimeter $_{\text {convex }}$ & Perimeter $_{\text {ellispse }}$ & Contour area & CAA (\%) \\
\hline $13.2 \mathrm{~mm}-1$ & 57961 & 975.23 & 908.56 & 57520.72 & 7.34 \\
\hline $13.2 \mathrm{~mm}-2$ & 57266 & 927.90 & 878.43 & 56836.18 & 5.63 \\
\hline $13.2 \mathrm{~mm}-3$ & 52468 & 880.24 & 843.69 & 52068.85 & 4.33 \\
\hline $13.2 \mathrm{~mm}-4$ & 41857 & 806.29 & 773.96 & 41458.99 & 4.18 \\
\hline $13.2 \mathrm{~mm}-5$ & 57146 & 971.47 & 898.94 & 56702.20 & 8.07 \\
\hline $13.2 \mathrm{~mm}-6$ & 44147 & 840.44 & 778.86 & 43771.14 & 7.91 \\
\hline $13.2 \mathrm{~mm}-7$ & 37663 & 763.59 & 713.62 & 37309.95 & 7.00 \\
\hline $13.2 \mathrm{~mm}-8$ & 50466 & 840.75 & 811.95 & 50077.90 & 3.55 \\
\hline $13.2 \mathrm{~mm}-9$ & 43108 & 811.00 & 774.72 & 42710.42 & 4.68 \\
\hline $13.2 \mathrm{~mm}-10$ & 50610 & 843.59 & 805.70 & 50204.63 & 4.70 \\
\hline $13.2 \mathrm{~mm}-11$ & 35759 & 739.78 & 677.90 & 35413.60 & 9.13 \\
\hline $13.2 \mathrm{~mm}-12$ & 46335 & 844.28 & 788.22 & 45954.89 & 7.11 \\
\hline $13.2 \mathrm{~mm}-13$ & 46514 & 822.90 & 801.70 & 46132.20 & 2.65 \\
\hline $13.2 \mathrm{~mm}-14$ & 33510 & 737.43 & 682.71 & 33180.99 & 8.01 \\
\hline $13.2 \mathrm{~mm}-15$ & 50487 & 899.28 & 850.95 & 50076.28 & 5.68 \\
\hline $13.2 \mathrm{~mm}-16$ & 41720 & 808.19 & 753.74 & 41365.96 & 7.22 \\
\hline $13.2 \mathrm{~mm}-17$ & 45394 & 802.52 & 764.28 & 45023.93 & 5.00 \\
\hline $13.2 \mathrm{~mm}-18$ & 48002 & 888.09 & 841.68 & 47602.06 & 5.52 \\
\hline $13.2 \mathrm{~mm}-19$ & 47407 & 872.33 & 833.09 & 46994.97 & 4.72 \\
\hline $13.2 \mathrm{~mm}-20$ & 44422 & 805.62 & 756.95 & 44039.77 & 6.43 \\
\hline $13.2 \mathrm{~mm}-21$ & 42072 & 854.49 & 756.05 & 41699.60 & 13.01 \\
\hline $13.2 \mathrm{~mm}-22$ & 41514 & 796.34 & 749.68 & 41140.93 & 6.22 \\
\hline $13.2 \mathrm{~mm}-23$ & 45712 & 842.15 & 788.87 & 45330.22 & 6.75 \\
\hline $13.2 \mathrm{~mm}-24$ & 47737 & 910.47 & 833.48 & 47315.84 & 9.24 \\
\hline $13.2 \mathrm{~mm}-25$ & 34337 & 763.56 & 698.06 & 34002.43 & 9.38 \\
\hline
\end{tabular}

Note: the data in this table were amount of pixels. 


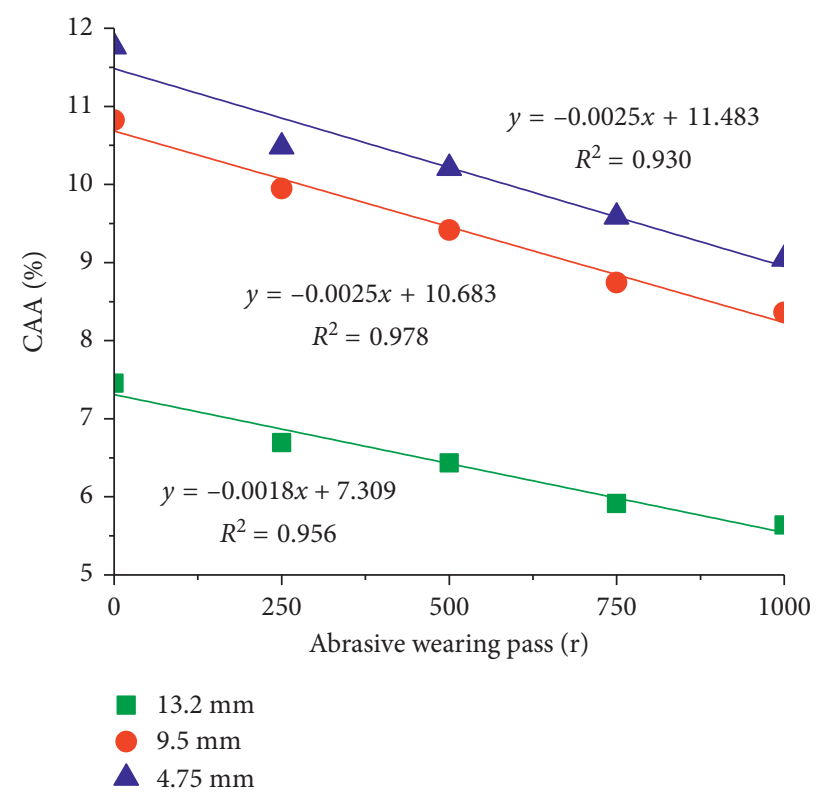

FIGURE 4: The CAA value over abrasive wearing pass.

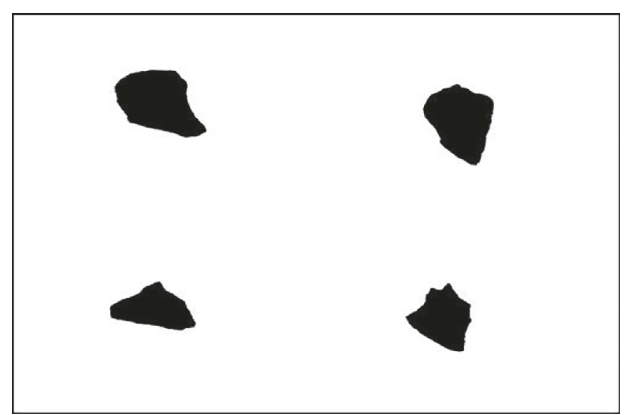

(a)

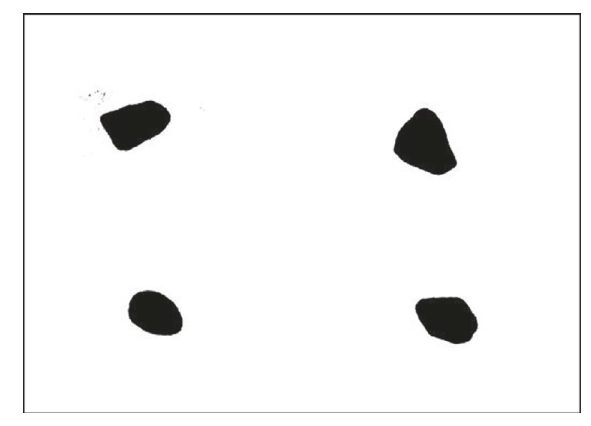

(b)

Figure 5: CAA of partial $4.75 \mathrm{~mm}$ limestone coarse aggregate before and after abrasive wearing. (a) CAA with 0 abrasive wearing pass. (b) CAA with 1000 abrasive wearing passes.

Figure 5(a) presented the $4.75 \mathrm{~mm}$ limestone coarse aggregate with 0 abrasive wearing pass had obvious fractured surface and angularity. However, undergoing 1000 abrasive wearing passes, the fractured surface and angularity almost disappeared and the shapes became more and more spherical, as shown in Figure 5(b). The CAA value also declined from $11.760 \%$ to $9.046 \%$.

4.2. Volumetric Characteristics. The WMA volumetric characteristics, such as air void, VMA, VFA, VCA, Marshall stability, and flow value, were tested, and the relationship between volumetric characteristics of WMA and CAA were plotted, as shown in Figure 6.

The test results showed that the volumetric characteristics of WMA had strong linear correlation with CAA. The lowest correlation coefficients $R^{2}$ were 0.858 . The higher the CAA value was, the higher the values for VMA, VCA, Marshall stability, and air void were, but the lower the values for VFA and flow value were. It was worthy to note that the higher CAA was easier to form aggregate interlocking, internal friction, and interactions with asphalt binder and hence resulted in greater mechanical stability and less deformation than with lower CAA value. Under the identical condition of asphalt binder content, the CAA had a significant effect on the asphalt binder distributing between aggregates. The CAA with higher value provided more structural asphalt binders and less free asphalt binders between aggregates than one with lower CAA value, which contributed to the Marshall stability in increment and VFA in reduction. Moreover, the higher CAA had higher compatibility, thus contributing to higher Marshall stability values.

4.3. Resistance to Rutting. Figure 7 illustrates the relationship between resistance to rutting of WMA and CAA. The test results indicated that the resistance to rutting of WMA had a good linear correlation with the CAA. The resistance to rutting of WMA increased with the CAA value increased. While the CAA value was $8.362 \%$, which meant the abrasive wearing pass was 1000 passes, the resistance to rutting of WMA had the lowest value and declined with 64.3\% 


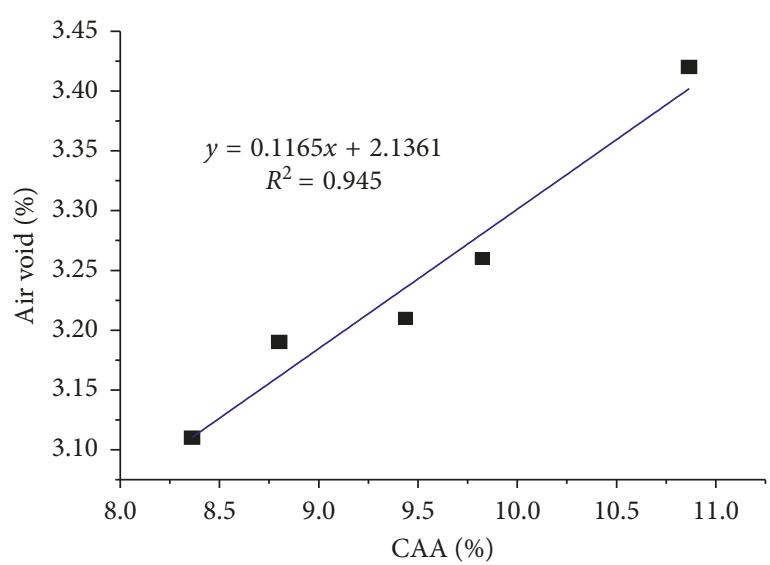

(a)

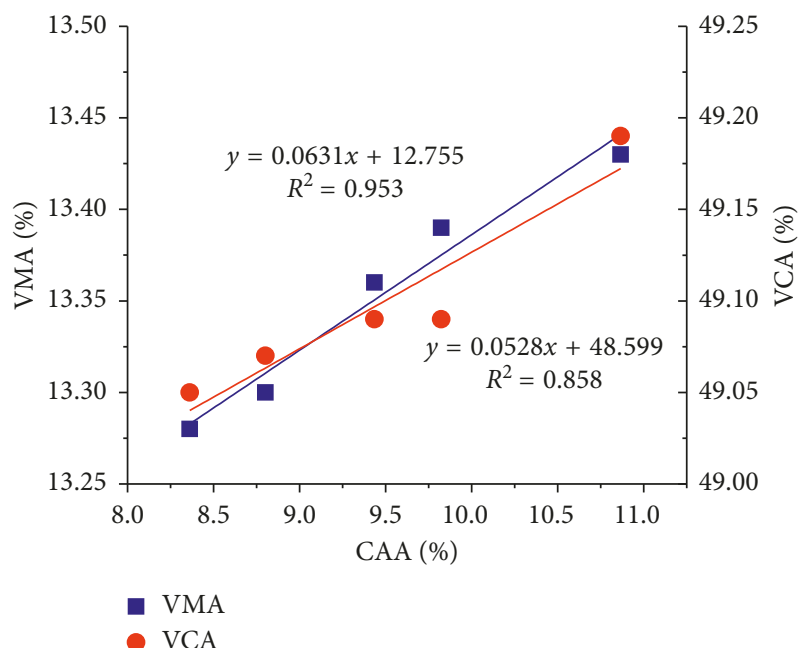

(c)

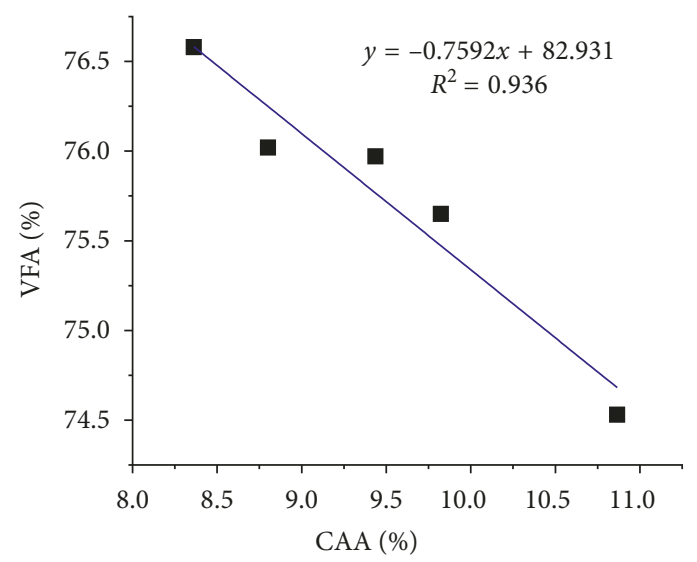

(b)

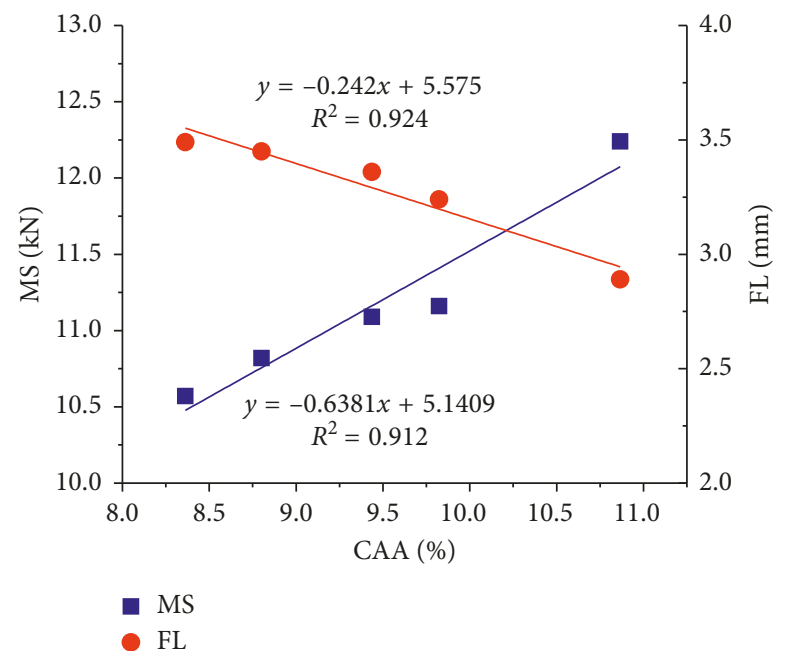

(d)

Figure 6: Volumetric characteristics of WMA over CAA.

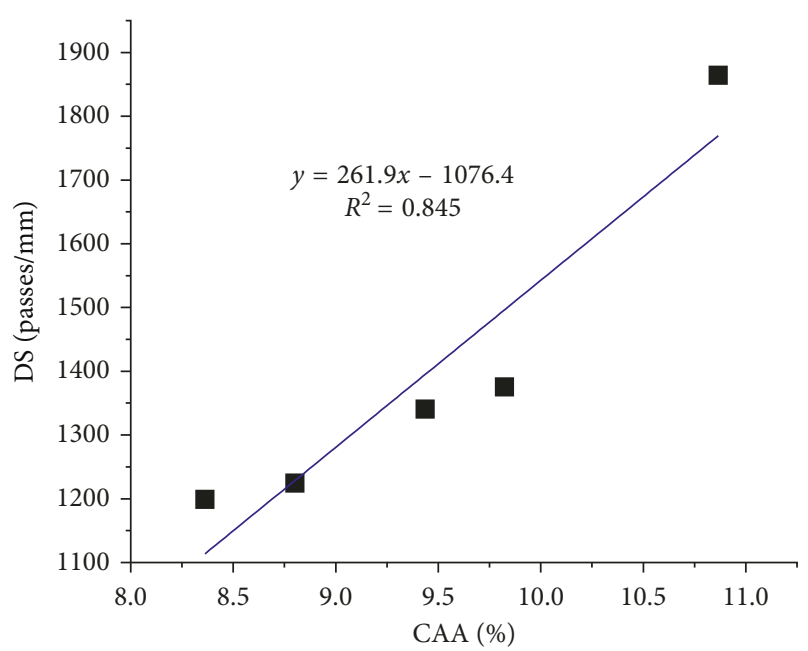

Figure 7: The resistance to rutting of WMA over CAA.

compared with the CAA value $10.866 \%$, which presented the abrasive wearing pass was 0 pass. It is worthy to note the higher CAA improved the potential to resistance to rutting of WMA.

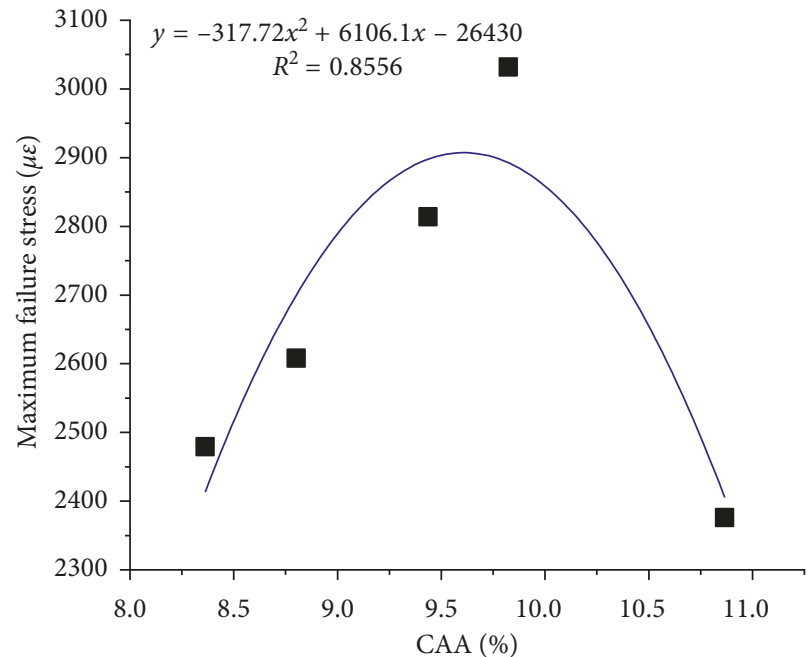

FIGURE 8: The resistance to thermal cracking of WMA over CAA.

4.4. Resistance to Thermal Cracking. In addition, Figure 8 presents the resistance to thermal cracking of WMA related to the CAA value. The test results indicated the resistance to 

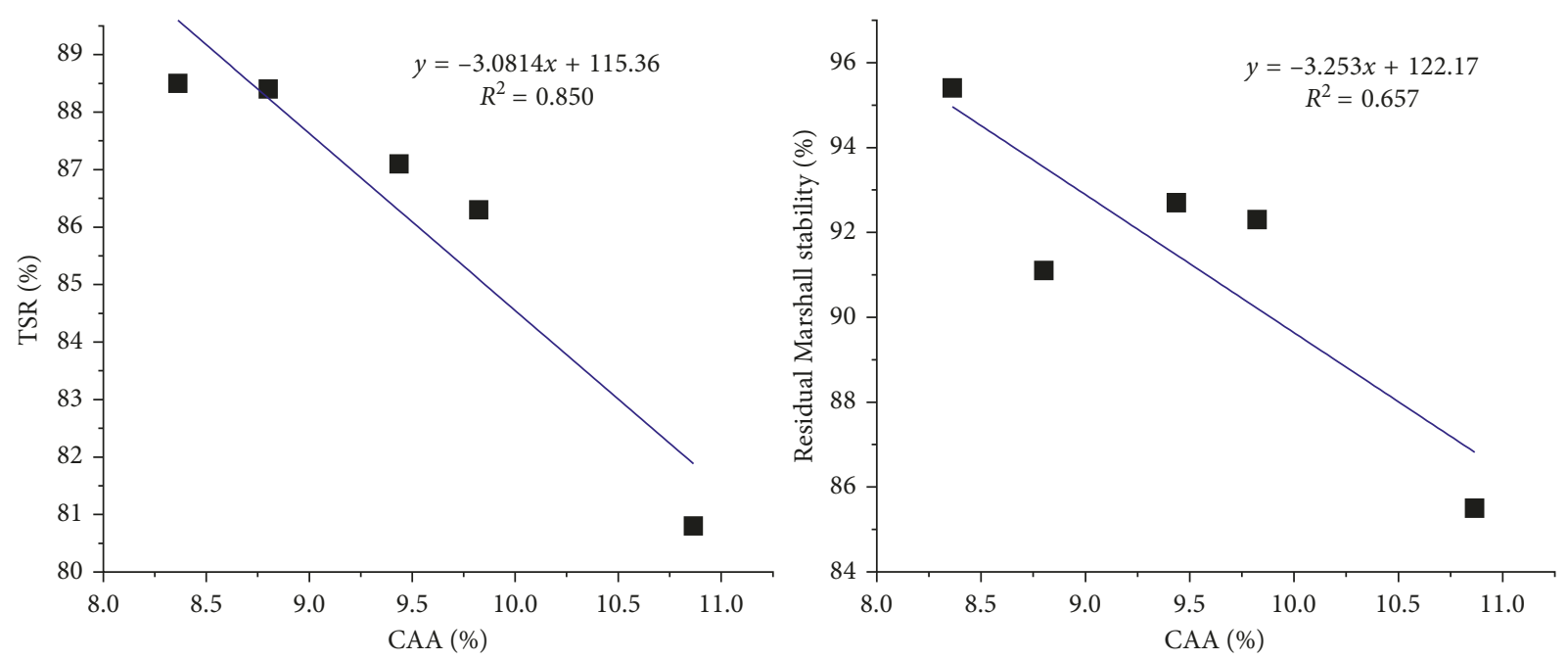

Figure 9: The moisture sensitivity of WMA over CAA.

thermal cracking of WMA had a good linear correlation with the CAA value except that the CAA value was $10.866 \%$. In other words, the resistance to thermal cracking of WMA had the lowest value when the CAA value was $10.866 \%$. It was worthy to note that the higher CAA value lowered the resistance to thermal cracking due to sharp corners that caused higher stress concentration. Ignoring the CAA value was $10.866 \%$, the resistance to thermal cracking of WMA increased with the CAA value increased linearly, which indicated that the optimum CAA value should be recommended while considering the resistance to thermal cracking of WMA.

4.5. Moisture Susceptibility. Along with the test results shown in Figures 7 and 8, the moisture susceptibility of WMA related to CAA is plotted in Figure 9. Figure 9 presents the relationship between TSR and residual Marshall stability of WMA with CAA, respectively.

The test results indicated the TSR and residual Marshall stability of WMA decreased with the CAA value increased. The correlation coefficients $R^{2}$ were 0.850 and 0.657 , respectively, which demonstrated the TSR and residual Marshall stability of WMA had a good linear correlation with CAA. This phenomenon could be explained that the higher CAA value produced higher air void, VMA, VCA, and lower VFA, which contributed to the more sensitivity at the present of water. The water was more prone to diffuse the interface between asphalt binder and aggregate with higher CAA value due to higher air void, VMA, and VCA. After undergoing loading condition, the location of higher stress concentration affected by higher CAA value was easily to develop numerous macrocracking, which resulted in lower moisture susceptibility.

4.6. Pearson Value. In this study, the CAA was called the independent variable and the volumetric characteristics and performances of WMA, such as VMA, VCA, TSR, and so on could be called the dependent variables. The independent variable (CAA) had a good correlation with dependent variables (VMA, VCA, TSR, and so on). So the Pearson
TABle 8: Pearson correlation coefficients between volumetric characteristics and CAA.

\begin{tabular}{lcccccc}
\hline $\begin{array}{l}\text { Volumetric } \\
\text { characteristics }\end{array}$ & $\begin{array}{c}\text { Air } \\
\text { void }\end{array}$ & VMA & VFA & VCA & MS & FL \\
\hline $\begin{array}{l}\text { Pearson correlation } \\
\text { coefficient }\end{array}$ & 0.979 & 0.982 & -0.967 & 0.945 & 0.967 & -0.971 \\
\hline
\end{tabular}

TABLE 9: Pearson correlation coefficients between performances and CAA.

\begin{tabular}{lccc}
\hline Performance & $\begin{array}{c}\text { Resistance } \\
\text { to rutting }\end{array}$ & $\begin{array}{c}\text { Resistance to } \\
\text { rutting and } \\
\text { thermal cracking }\end{array}$ & $\begin{array}{c}\text { Moisture } \\
\text { susceptibility }\end{array}$ \\
\hline $\begin{array}{l}\text { Pearson } \\
\text { correlation } \\
\text { coefficient }\end{array}$ & 0.940 & 0.990 & -0.942 \\
\hline
\end{tabular}

product-moment correlation coefficient was employed to judge the influencing degree of CAA on the different dependent variables. The Pearson value was between -1 and +1 . The value close to +1 meant the CAA had a strong positive influencing degree on the dependent variables. The value close to -1 demonstrated the CAA had a strong negative influencing degree on the dependent variables. Thus, the Pearson value between the independent variable (CAA) and dependent variables (VMA, VCA, TSR, and so on) were calculated and analyzed [36], as seen in Tables 8 and 9.

Table 8 indicates that the ranking of Person correlation coefficient was VMA, followed by air void, Marshall stability, and VCA, which presented the VMA was strongly affected by the CAA. However, the Pearson correlation coefficient for flow value and VFA was -0.971 and -0.967 that was very close to -1 . The absolute Pearson value for flow value was higher than the one for VFA, which indicated the CAA influenced the flow value more heavily compared with the VFA.

Form Table 9, it could be found that the CAA value and the resistance to rutting and thermal cracking of WMA had a strong proportional relation, respectively, because the Pearson correlation coefficient was 0.940 and 
0.990 which was very close to +1 . However, the CAA value and moisture susceptibility of WMA had strong inverse proportional relationship for the Pearson correlation coefficient of -0.942 .

\section{Conclusions}

This study investigated the effect of CAA on performances of WMA through experimental tests. Based on this study, the following summary and conclusions could be made:

(i) The DIP approach could be used to characterize the CAA. The limestone CAA value decreased as the abrasive wearing passes increased and the CAA had a good linear correlation with the abrasive wearing passes. Smaller size coarse aggregate had a higher CAA value due to more crushing, but once it was worn, it was more prone to loss its angularity compared to the larger size coarse aggregate.

(ii) CAA value had a significant effect on the volumetric characteristics, such as air void, VFA, VCA, VMA, flow value, and Marshall stability, of WMA. Except VFA and flow value, the air void, VMA, VCA, and Marshall stability of WMA increased with the CAA value increased, which indicated the higher CAA value with more fractures and specific surface areas contributing for better stone-stone skeleton.

(iii) CAA also affected the performances, such as resistance to rutting and thermal cracking, moisture susceptibility, of WMA. Higher CAA value improved the potential to resistance to rutting of WMA. However, the higher CAA value was not suitable to enhance the resistance to thermal cracking of WMA due to sharp corners that caused higher stress concentration. Besides, the higher CAA value negatively influenced the moisture susceptibility of WMA. WMA was more prone to develop numerous macrocracking, which resulted in lower moisture sensitivity with higher CAA value inducing higher air void, VCA, and VMA.

(iv) The Pearson product-moment correlation coefficient was employed to judge the correlation between the independent variable (CAA) and dependent variables (VMA, VCA, TSR, and so on). The CAA value had a strong effect on the VMA and the resistance to thermal cracking of WMA due to their Person values was very close to +1 . Also, the CAA value had a strong inverse effect on the flow value and the moisture susceptibility of WMA for their Pearson values was very close to -1 .

(v) The relationships between CAA value and performances of WMA could be used to develop specifications for the selection of aggregates that would improve the mixture performances. Meanwhile, other coarse aggregate properties such as surface texture, hardness, affinity for asphalt cement, and so on must also be taken into account for evaluating the mixture performances.

\section{Data Availability}

The data used to support the findings of this study are available from the corresponding author upon request.

\section{Conflicts of Interest}

The authors declare that they have no conflicts of interest.

\section{Acknowledgments}

This study is sponsored by National Natural Science Foundation of China (nos. 51478028 and 51778038) and Program for Changjiang Scholars and Innovative Research Team in University (IRT_17R06). Thanks also go to Mr. Gao Jinqi for his help during the experiment of this research.

\section{References}

[1] B. Kheradmand, R. Muniandy, L. T. Hua, R. B. Yunus, and A. Solouki, "An overview of the emerging warm mix asphalt technology," International Journal of Pavement Engineering, vol. 15, no. 1, pp. 79-94, 2013.

[2] S. Hesami, H. Roshani, G. Hossein Hamedi, and A. Azarhoosh, "Evaluate the mechanism of the effect of hydrated lime on moisture damage of warm mix asphalt," Construction and Building Materials, vol. 47, no. 5, pp. 935941, 2013.

[3] O. Kristjansdottir, S. Muench, L. Michael, and G. Burke, "Assessing potential for warm-mix asphalt technology adoption," Transportation Research Record: Journal of the Transportation Research Board, vol. 2040, pp. 91-99, 2007.

[4] B. Prowell, G. Hurley, and E. Crews, "Field performance of warm-mix asphalt at national center for asphalt center for asphalt technology test track," Transportation Research Record: Journal of the Transportation Research Board, vol. 1998, no. 1, pp. 96-102, 2007.

[5] F. Xiao, J. Jordan, and S. N. Amirkhanian, "Laboratory investigation of moisture damage in warm-mix asphalt containing moist aggregate," Transportation Research Record: Journal of the Transportation Research Board, vol. 2126, pp. 115-124, 2009.

[6] W. Gong, Investigation of Moisture Susceptibility of Warm Mix Asphalt (WMA) Mixes through Laboratory Mechanical Testing, M.Sc. thesis, Worcester Polytechnic Institute, Worcester, MA, USA, 2011.

[7] B. Huang, X. Chen, X. Shu, E. Masad, and E. Mahmoud, "Effects of coarse aggregate angularity and asphalt binder on laboratory-measured permanent deformation properties of HMA," International Journal of Pavement Engineering, vol. 10, no. 1, pp. 19-28, 2009.

[8] L. P. Leon and R. Charles, "Aggregate angularity on the permanent deformation zones of hot mix asphalt," Global Journal of Research in Engineering, vol. 15, no. 3, pp. 25-29, 2015.

[9] L. T. Souza, Y.-R. Kim, F. V. Souza, and L. S. Castro, "Experimental testing and finite-element modeling to evaluate the effects of aggregate angularity on bituminous mixture performance," Journal of Materials in Civil Engineering, vol. 24, no. 3, pp. 249-258, 2012.

[10] C. Rao, E. Tutumluer, and I. T. Kim, "Quantification of coarse aggregate angularity based on image analysis," Transportation 
Research Record: Journal of the Transportation Research Board, vol. 1787, no. 1, pp. 117-124, 2002.

[11] T. Pan and E. Tutumluer, "Quantification of coarse aggregate surface texture using image analysis," Journal of Testing and Evaluation, vol. 35, no. 2, pp. 177-186, 2007.

[12] X. Shu, B. Huang, X. Chen, and L. Robison, "Effect of coarse aggregate angularity on rutting performance of HMA," in Proceedings of the GeoShanghai International Conference 2006: Pavement Mechanics and Performance, pp. 126-133, Shanghai, China, June 2006.

[13] H.-N. Wang, P.-W. Hao, Q.-Y. Xiao et al., "Digital image evaluation method for angularity of coarse aggregates," Journal of Southeast University (Natural Science Edition), vol. 38, no. 4, 2008.

[14] M.-Y. Yuan, Study on Aggregate Angularity Influence on the Performance of Asphalt Mixture, M.Sc. thesis, Chang'an University, Xi'an, China, 2011.

[15] Z. Liu, Y. Yang, Q. Liu et al., "Coarse aggregate angularity description method and technical standard of asphalt pavement," China Journal of Highway and Transport, vol. 23, no. 4, pp. 8-14, 2010.

[16] G. Chen, Y. Tan, K. Shi et al., "Influence of coarse aggregate angularity on hot-mix asphalt properties," Road Traffic Science and Technology, vol. 23, no. 3, pp. 6-9, 2006.

[17] L. Leon and R. Charles, "Impact of coarse aggregate type and angularity on permanent deformation of asphalt concrete," in Proceedings of the Computational Methods and Experimental Measurements XVII, vol. 59, pp. 303-313, Opatija, Croatia, May 2015.

[18] R. E. Link and C. Y. Kuo, "Correlating permanent deformation characteristics of hot mix asphalt with aggregate geometric irregularities," Journal of Testing and Evaluation, vol. 30, no. 2, pp. 136-144, 2002.

[19] T. Al-Rousan, E. Masad, E. Tutumluer, and T. Pan, "Evaluation of image analysis techniques for quantifying aggregate shape characteristics," Construction and Building Materials, vol. 21, no. 5, pp. 978-990, 2007.

[20] E. Masad and J. W. Button, "Unified imaging approach for measuring aggregate angularity and texture," ComputerAided Civil and Infrastructure Engineering, vol. 15, no. 4, pp. 273-280, 2000.

[21] ASTM D5821-95, Standard Test Method for Determining the Percentage of Fractured Particles in Coarse Aggregate, American Society of Testing and Materials, West Conshohocken, PA, USA, 1999.

[22] AASHTO TP 61, Standard Test Method Determining the Percentage of Fracture in Coarse Aggregate, AASHTO Provisional Standards, AASHTO, Washington, DC, USA, 2003.

[23] C. Chandan, K. Sivakumar, E. Masad, and T. Fletcher, "Application of imaging techniques to geometry analysis of aggregate particles," Journal of Computing in Civil Engineering (ASCE), vol. 18, no. 1, pp. 75-82, 2004.

[24] N. H. Maerz, "Technical and computational aspects of the measurement of aggregate shape by digital image analysis," Journal of Computing in Civil Engineering (ASCE), vol. 18, no. 1, pp. 10-18, 2004.

[25] N. H. Maerz and M. Lusher, "Measurement of flat and elongation of coarse aggregate using digital image processing," Transportation Research Record: Journal of the Transportation Research Board, vol. 2126, pp. 1-14, 2001.

[26] C. F. Mora and A. K. H. Kwan, "Sphericity, shape factor, and convexity measurement of coarse aggregates for concrete using digital image processing," Cement and Concrete Research, vol. 30, no. 3, pp. 351-358, 2000.
[27] M. F. Carlos, Particle Size and Shape Analysis of Coarse Aggregate using Digital Image Processing, Ph.D. thesis, University of Hong Kong, Pokfulam, Hong Kong, 2000.

[28] T. Fletcher, Aggregate Imaging System for Characterizing Fine and Coarse Aggregate Shape, M.Sc. thesis, Department of Civil and Environmental Engineering, Washington State University, Pullman, WA, USA, 2002.

[29] T. Fletcher, C. Chandan, E. Masad, and K. Sivakumar, "Aggregate imaging system (AIMS) for characterizing the shape of fine and coarse aggregates," Transportation Research Record: Journal of the Transportation Research Board, vol. 1832, pp. 67-77, 2002.

[30] G. A. Swift, Characterization of Coarse Aggregate Angularity using Digital Image Processing, M.Sc. thesis, Department of Civil and Environmental Engineering, Missouri University of Science and Technology, Rolla, MI, USA, 2007.

[31] ASTM C131, Standard Test Method for Resistance to Degradation of Small-Size Coarse Aggregate by Abrasion and Impact in the Los Angeles Machine, American Society of Testing and Materials, West Conshohocken, PA, USA, 2006.

[32] ASTM D1559, Standard Method of Test for Resistance to Plastic Flow of Bituminous Mixtures using Marshall Apparatus, American Society of Testing and Materials, West Conshohocken, PA, USA, 2006.

[33] ASTM D2726, Standard Test Method for Bulk Specific Gravity and Density of Non-Absorptive Compacted Bituminous Mixtures, American Society of Testing and Materials, West Conshohocken, PA, USA, 2006.

[34] AASHTO T283, Resistance of Compacted Bituminous Mixture to Moisture-Induced Damage, AASHTO Provisional Standards, AASHTO, Washington, DC, USA, 2010.

[35] Research Institute of Highway Communications, Standard Test Methods of Bitumen and Bituminous Mixtures for Highway Engineering (JTG E20-2011), Renmin Communication Press, Beijing, China, 2011.

[36] J. Cohen, P. Cohen, S. West, and L. Aiken, Applied Multiple Regression/Correlation Analysis for the Behavioral Sciences, Psychology Press, Hove, UK, 3rd edition, 2002. 


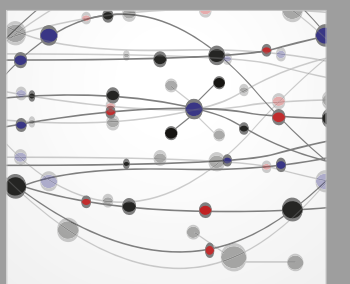

The Scientific World Journal
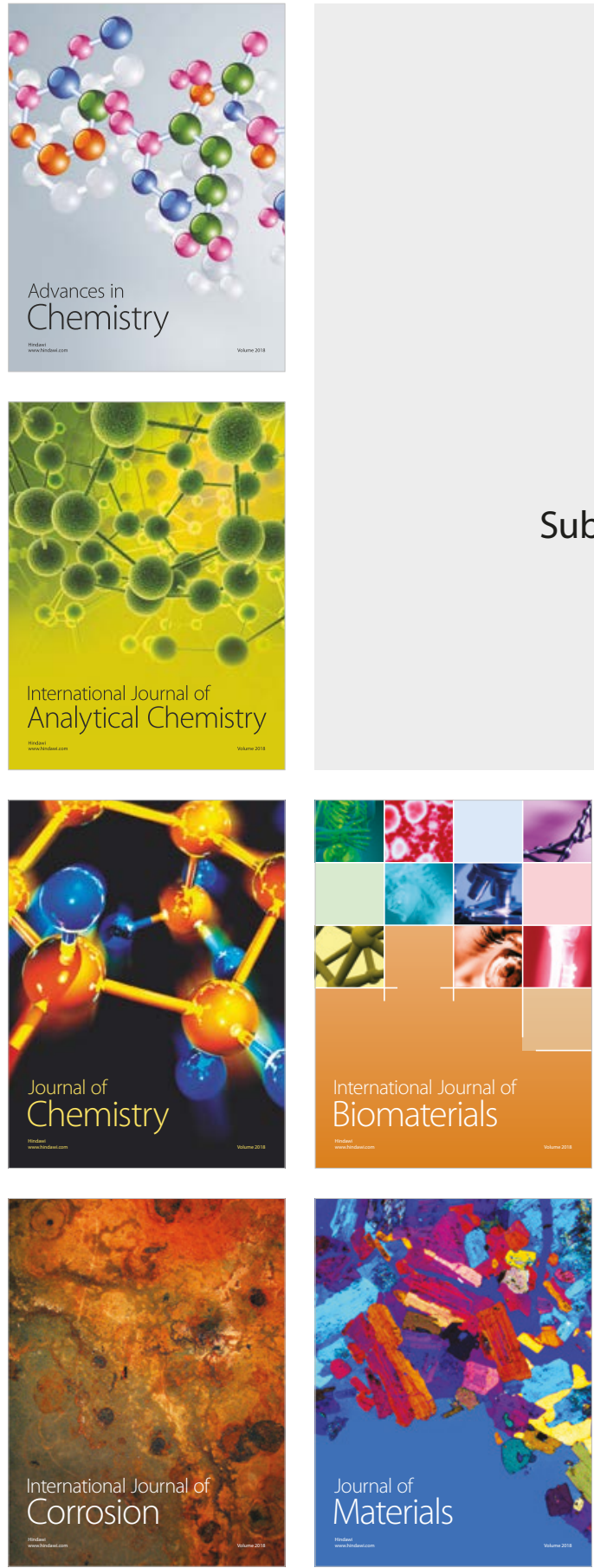

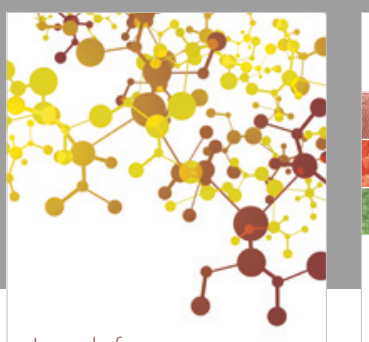

Journal of

Applied Chemistry
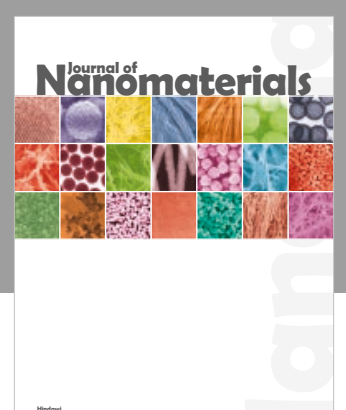

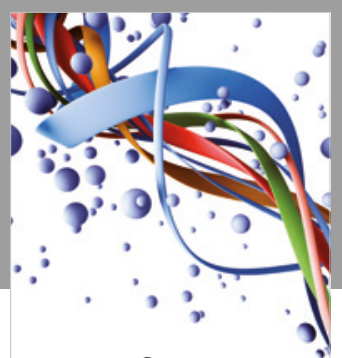

Scientifica

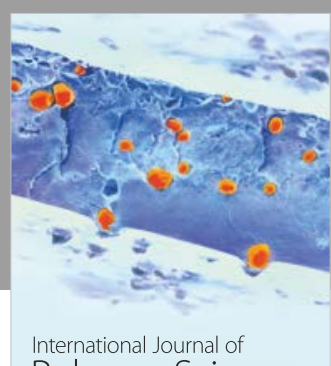

Polymer Science

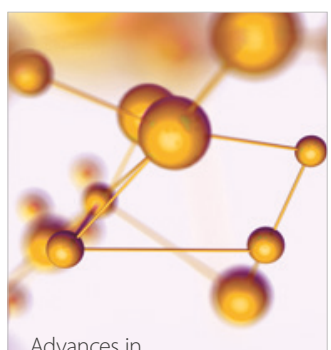

Physical Chemistry
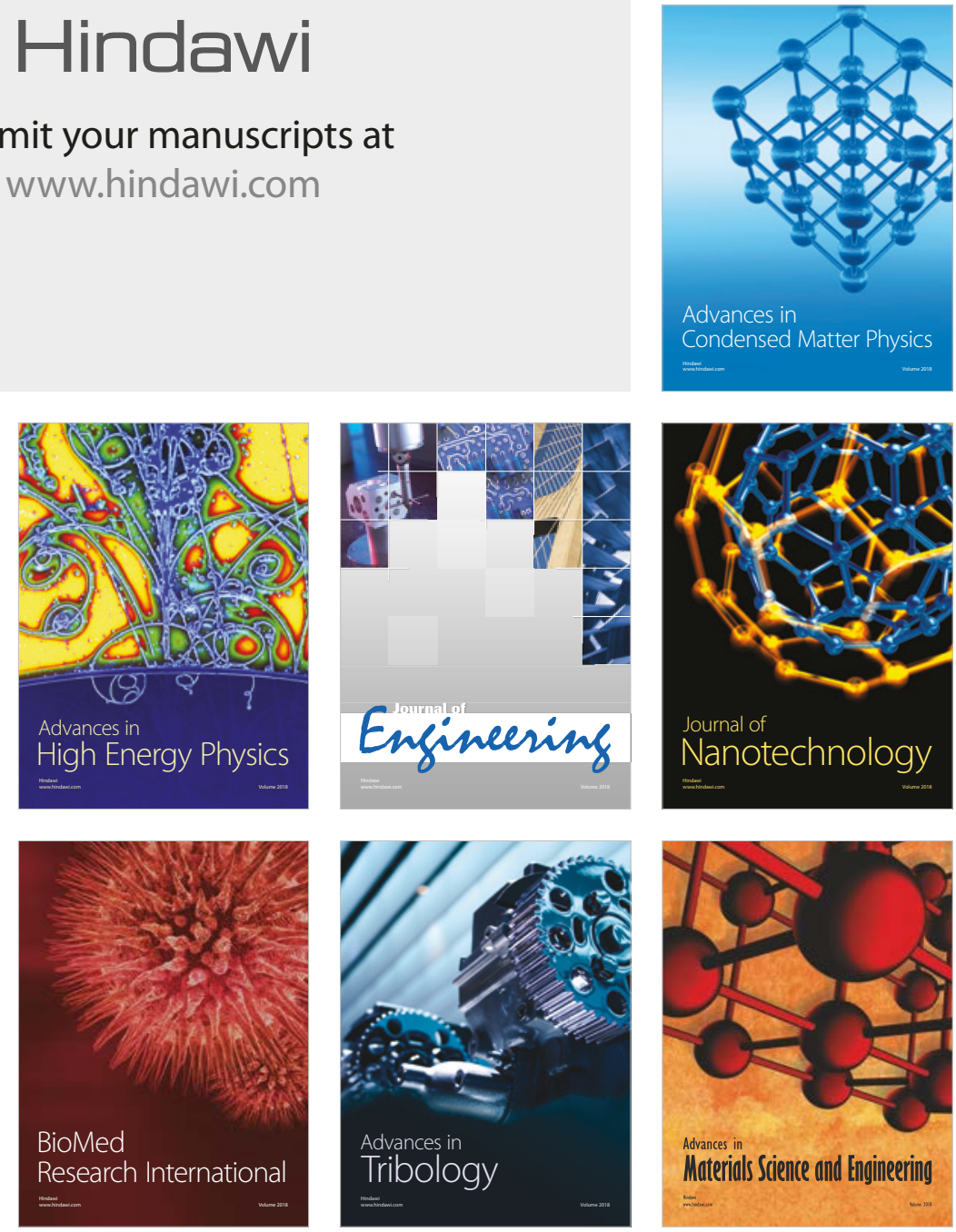